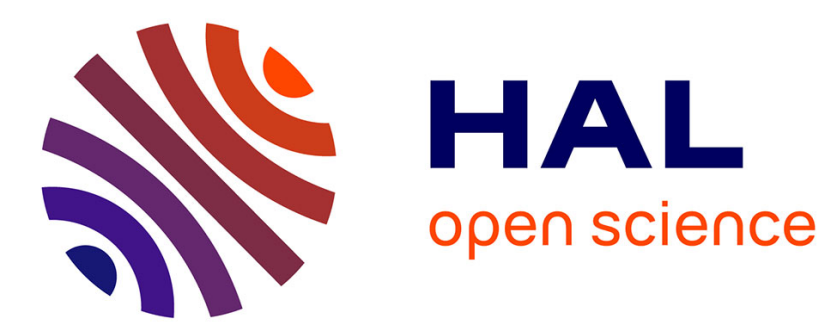

\title{
Dynamic Behaviour of Polycarbonate/Polyurethane Multi-Layer for Transparent Armor
}

\author{
W. Toqueboeuf, B. Mortaigne, C. Cottenot
}

\section{To cite this version:}

W. Toqueboeuf, B. Mortaigne, C. Cottenot. Dynamic Behaviour of Polycarbonate/Polyurethane Multi-Layer for Transparent Armor. Journal de Physique IV Proceedings, 1997, 07 (C3), pp.C3-499C3-504. 10.1051/jp4:1997386 . jpa-00255543

\section{HAL Id: jpa-00255543 https://hal.science/jpa-00255543}

Submitted on 1 Jan 1997

HAL is a multi-disciplinary open access archive for the deposit and dissemination of scientific research documents, whether they are published or not. The documents may come from teaching and research institutions in France or abroad, or from public or private research centers.
L'archive ouverte pluridisciplinaire HAL, est destinée au dépôt et à la diffusion de documents scientifiques de niveau recherche, publiés ou non, émanant des établissements d'enseignement et de recherche français ou étrangers, des laboratoires publics ou privés. 


\title{
Dynamic Behaviour of Polycarbonate/Polyurethane Multi-Layer for Transparent Armor
}

\author{
W. Toqueboeuf, B. Mortaigne and C. Cottenot*
}

\author{
DGA/CREA, Département Matériaux en Conditions Sévères, 16 bis avenue Prieur de la Côte d'Or \\ 94114 Arcueil cedex, France \\ DGA/CREA, Département Polymères et Composites, 16 bis avenue Prieur de la Côte d'Or, \\ 94114 Arcueil cedex, France
}

\begin{abstract}
This paper deals with the study of the dynamic behaviour of layered Polycarbonate (PC)/Polyurethane (PU) polymers used in lightweight transparent armor bilayer concept. In fact, dimensioning and optimizing this armor concepts need a determination and an understanding of behaviour not only of the multi-layer but also of each component (PC and PU). Thus after an adaptation of dynamic compressive tests in different configurations, it appears that the initial multi-axial prestress of PU is one of the most important parameter for material and layered response. A numerical approach carried out with a monodimensional finite difference code is made to analyze more accurately the system response.

Résumé : L'objectif de ce travail est d'étudier le comportement dynamique des feuilletages de Polycarbonate (PC)/Polyuréthanne (PU) utilisés en face arrière de concept de blindages légers transparents bicouche. En effet, le dimensionnement de ces concepts et leur optimisation passe par une détermination et compréhension du comportement non seulement du feuilletage, mais aussi de chacun des constituants (PC el PU). Ainsi après avoir adapté des essais dynamiques de compression et testé diverses configurations, il apparait que l'état de précontrainte multi-axiale du PU modifie considérablement son comportement et celui de l'assemblage. Une approche numérique menée à l'aide d'un code monodimensionnel en différences finies permet d'analyser plus finement la réponse de l'ensemble.
\end{abstract}

\section{INTRODUCTION}

There is today a growing need for light transparent armour concepts against small and medium Armour Piercing (AP.) projectiles, which can fulfill the mass and/or thickness specifications of helicopters or light armored vehicle programmes. To agree with these specifications, it appears that bilayer concepts are probably the light armours showing the greatest interest against an AP $12.7 \mathrm{~mm}$ threat. They consist of an association of two materials, called respectively front layer and back layer, each of them playing a specific role.

It could be also noticed that a high synergy exists between both materials used in the bilayer armor. Hence the behaviour impact depends on the global response of the target. These multilayer concepts are classically used for opaque armours and reveal a high weight saving when compared with classic monolithic armours (steel or aluminium alloys) [1]. Also, transparent lightweight armors with a transparent ceramic front face, such as Sapphire or Magnesie Spinel, appear to be particularly efficient when associated with a transparent polymer back face [2]. The front layer, generally a ceramic, has to break and slow down the incident projectile and also to spatially and temporally spread the impact energy towards the back layer by the creation of a cone crack. The back layer has to ensure a structural function but also to store the impact energy and to stop the projectile and ceramic fragments. In fact, considering the muzzle projectile velocity (around $830 \mathrm{~m} / \mathrm{s}$ ), this value is low compared with the shock wave velocity $(\approx 9000 \mathrm{~m} / \mathrm{s})$ induced in the ceramic by impact. Thus the back layer is submitted to a dynamic solicitation, and the plastic deformation is one of the main modes for energy absorption. However, localization of the polymer deformation may occur, inducing a premature failure of the material. It is thus necessary that the level of incident energy matches the capacity of polymer deformation.

The use of a back face composed of polycarbonate (PC) layers separated by thin polyurethane (PU) rubber layers seems very attractive, since the rubber layers are able to spread temporally and spatially the impact energy. Then the level of transmitted energy becomes compatible with the PC capacity of deformation.

Before dimensioning and optimizing transparent armor concepts, the behaviour of the multi-layer and of each component (PC and PU) has to be determined. 
Thus, after a presentation of the main thermal, physical and chemical characteristics of PC and PU, this paper deals with an experimental approach of the behaviour of these materials (alone or layered) under quasi-static and dynamic solicitations, using Hopkinson bars apparatus. Special configuration hats been defined to study the influence of the initial prestresses of the rubber layers (usually induced in layered system) during process. To analyze finely the response of each components of the system, a specific mono dimensional finite element different code has been developed.

\section{MATERIAL AND MULTI-LAYERED PRESENTATION}

To understand the behaviour of the polymer layer, it is necessary to obtain a good knowledge of eich component properties. Principal physical characteristics of polymers used are presented.

\subsection{Polycarbonate}

A lot of works exhibit properties of PC [3-8]. Thus, from bibliography, main points are summarized and presented hereafter. The PC has been supplied by General Electric as PC Lexan. This material is a subcristaline polymers which points out two main mechanical transitions [3] :

$-\alpha$ relaxation linked to the glass transition around $150^{\circ} \mathrm{C}$;

$-\beta$ secondary relaxation around $-80^{\circ} \mathrm{C}$.

This point is important by the fact that dynamic mechanical properties are directly linked to the polyner transitions [9] and this dependence is expressed by important changes of mechanical properties as function of temperature or strain rate. Quasi-static principal physical properties of PC are presented in table 1. These values seem not to be affected in temperature range $\left[-70^{\circ} \mathrm{C} ; 140^{\circ} \mathrm{C}\right]$.

About dynamic behaviour of PC, Billington \& al. [4] have performed compression tests using Hopkinson bars apparatus. Significant results on polymer behaviour are presented on Figure 1 and reveal thal increase in striker impact velocity leads to an inflation of stress / strain loops. The curves stress / strain asped implies that two distinguishable rheological states exist for PC polymer. As a consequence, the material behaviour in the impact velocity range applied is limited by the two PC behaviour curves :

- quasi-static curve noticed $[\sigma(\infty) ; \varepsilon(\infty)]$;

- "ideal" instantaneous characteristics noticed $[\sigma(0) ; \varepsilon(0)]$ and obtained considering the common par! of each initial individual stress-strain loop.

Steer and al. [3] shows the elastoviscoplastic behaviour of Lexan and the importance of plastic strain even at high velocity.

Table 1: Static mechanical properties of PC

\begin{tabular}{|c|c|}
\hline Density & 1.2 \\
\hline $\mathbf{E}(\mathbf{G P a})$ & 2.35 \\
\hline $\mathrm{V}$ & 0.38 \\
\hline$\sigma_{\mathrm{y}}(\mathbf{M P a})$ & 60 \\
\hline$\varepsilon_{\text {el }}(\%)$ & 7 \\
\hline$\sigma_{\text {ult }}(\mathbf{M P a})$ & 70 \\
\hline$\varepsilon_{\text {ult }}(\%)$ & $>110$ \\
\hline
\end{tabular}

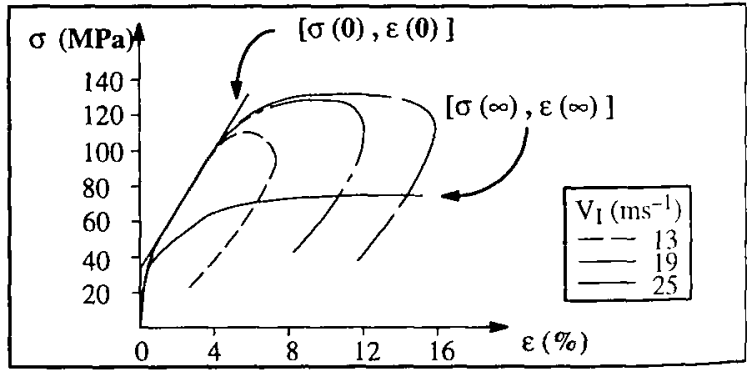

Figure 1: behaviour of PC; sensibility of striker impact velocily

\subsection{Polyurethanne}

The PU used has been supplied by the French company Sully Produits Speciaux (SPS) as film bonding exhibiting a thickness of $1.25 \mathrm{~mm}$. This material is known to present, when used alone, a rubber behaviour. Preliminary physico-chemical characterisation has been performed [10] and most important physical properties of $\mathrm{PU}$ at $20^{\circ} \mathrm{C}$ are given in table 2 .

Table 2: Characteristics of PU

\begin{tabular}{|c|c|}
\hline Density & 1.19 \\
\hline $\mathbf{E}(\mathbf{M P a})$ at $20^{\circ} \mathbf{C}$ & 4 \\
\hline $\mathbf{G}(\mathbf{M P a})$ at $20^{\circ} \mathbf{C}$ & 5 \\
\hline $\boldsymbol{V}$ & 0.48 \\
\hline $\boldsymbol{\varepsilon}_{\text {ult. }}(\boldsymbol{\%})$ & $>700$ \\
\hline
\end{tabular}


We have to focus on PU characteristics when it is included in a multi-layer with residual thermal prestresses and lateral confinement ( $v$ reaching 0 ). Moreover, PU exhibits a glass transition around $-10^{\circ} \mathrm{C}$ which induced an high evolution of physical properties essentially in the range of investigated temperature $\left[0^{\circ} \mathrm{C}\right.$ and $50^{\circ} \mathrm{C}$ ) (see Figure 2). This will influence deeply the multilayer PC/PU behaviour.

\subsection{Multi-layer}

In this part, we have focused our investigation on a simple

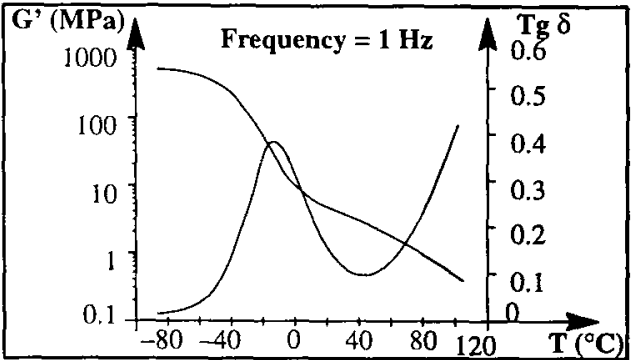

Figure 2: PU thermomechanical spectra with shear mode symmetrical layered of PC ( $3 \mathrm{~mm}) / \mathrm{PU}(3 \mathrm{~mm}) / \mathrm{PC}(3 \mathrm{~mm})$ supplied by SPS. Specific tests performed by CREA on process indicated that the joining of the different layers would be made on dry materials without any interface additives. A correct bonding between PC and PU could be obtained using a furnace temperature around $110^{\circ} \mathrm{C}$, sample being degazed under vacuum. This means that considering the difference of thermal expansion index and the Young modulus of each polymer, the elaboration process does not induced any residual thermal stress in the two PC layers in opposition with PU layer which is under a biaxial residual thermal stress as mentioned before.

\section{SPECIFIC COMPRESSIVE POLYURETHANE BEHAVIOUR}

A lot of work on PC behaviour are available on litterature [4]-[8]. Considering the fact that first, during an impact, compression is the main mode of loading, and secondly that the PU behaviour is affected by thermal residual stress, it appears very useful to focus our investigation on the PU biaxial prestress influence.

\subsection{Polyurethane configuration test investigated}

Based on the following hypothesis for multilayered PC/PU/PC such as:

- the gluing makes the interfaces motionless;

- the area of the multilayered system is considered infinite compared with the interaction area during an impact which induced, in first approximation, that lateral displacements of PU are negligible.

These hypothesis allow us to consider the PU in the layered system laterally confined. The evaluation of confinement and interface influence appears very interesting. In order to take into account different points mentioned before, disk of $1.25 \mathrm{~mm}$ thick and $30 \mathrm{~mm}$ diameter of PU were confined during the compression characterization using the experimental devices presented on Figure 3(a) and 3(b) for quasi-static and dynamic solicitation.
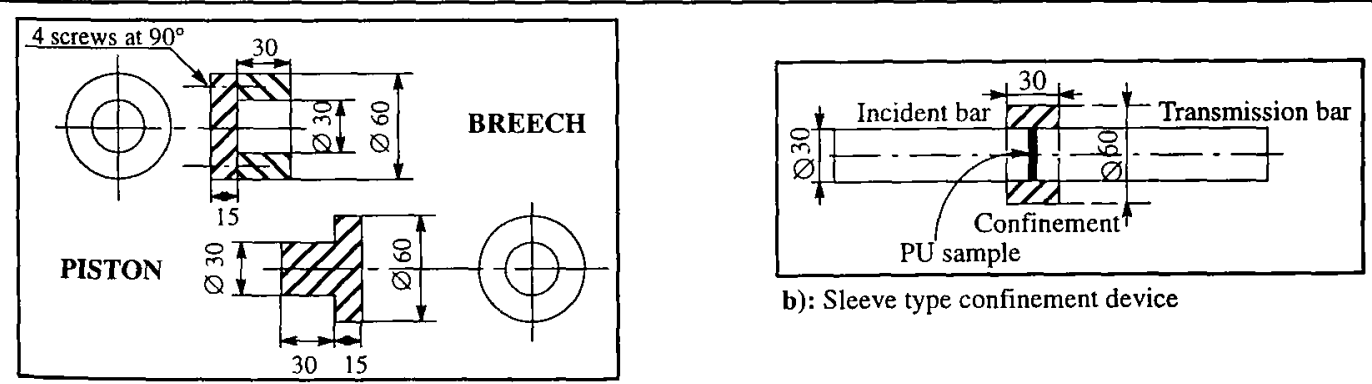

b): Sleeve type confinement device

a): Breech/Piston confinement device

Figure 3: Quasistatic and dynamic confinement devices

Based on an elastic linear isotropic field, a mechanical analysis of the confined test configuration is made (see figure 4). Results show that the hydrostatic compressibility modulus $\mathrm{K}$ is approached with an error around $4 \mathrm{G} / 3$. In our case this is estimated at about $7 \mathrm{MPa}$ which is negligible compared to the value of $\mathrm{K}(\approx 2 \mathrm{GPa})$. 


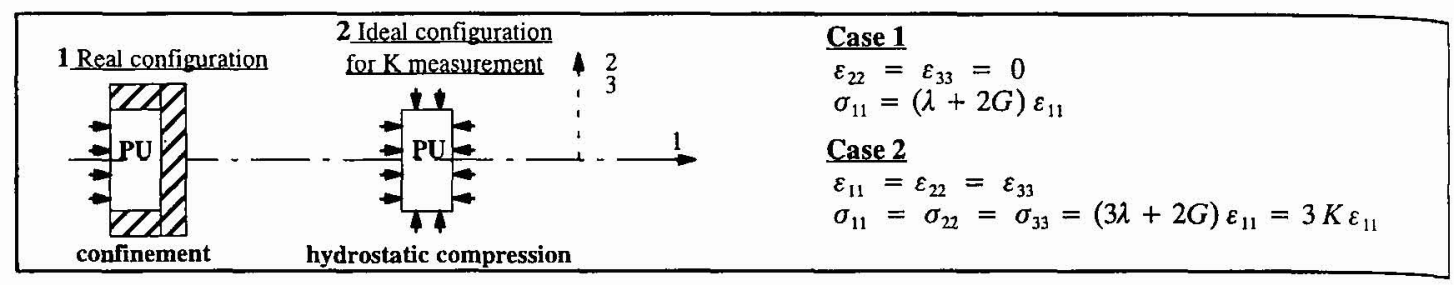

Figure 4: Analysis of $\mathrm{K}$ modulus approach

\subsection{Quasi-static compression test}

The first approach has been made in a quasi-static solicitation mode. Typical results presented on Figure $j_{a}$ points out the influence of parameter such as bonding and confinement on the mechanical behaviour of PU.

This indicates that confined PU exhibits a reversible elastic behaviour with a $\mathrm{K}$ value reaching $1.9 \mathrm{GPa}$ quite similar to the PU in a multi-layered system supposed laterally confined.

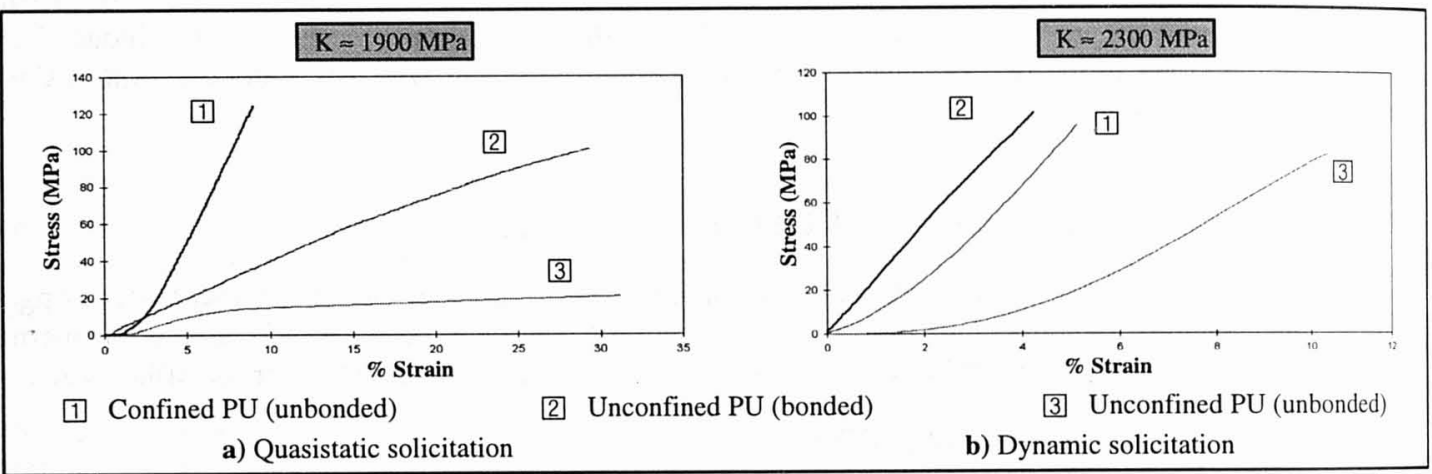

Figure 5: Intluence of bonding and confinement on compression behaviour of PU

\subsection{Dynamic compression test}

The PU behaviour under high strain rates has been studied using Hopkinson bars apparatus [4] to deal with the dynamic ballistic test conditions. If this technique is well known for metallic material, some problem exhibit for polymers studies and especially for PU material considering the low wave velocity which makes the test results analysis critical.

A sleeve type confinement device has been used to confine the PU (see Figure 3b). In order to obtain a stresses pseudo-equilibrium in the PU sample, a projectile of $1 \mathrm{~m}$ long has been used to have the longest incident signal. With this condition, a numerical approach indicates that this pseudo-equilibrium is reached about $35 \mu$ s, i.e. before the release of tensile wave in the transmission bar.

Taking into account bonding and confinement parameters, results obtained are presented in Figure 56 . The strain rate influence is clearly put in evidence in each case and more especially for bonded samples which present a behaviour similar to confined samples. Thus, here again confined PU exhibits a reversible elastic behaviour with a $\mathrm{K}$ value reaching $2.3 \mathrm{GPa}$.

\subsection{Conclusions and prospects}

Quasi-static and dynamic compression tests performed allow us to notice different points:

- the PU behaviour is quite similar under dynamic and quasi-static loadings. The hydrostatic compressibility modulus approached is practically the same,

- the influence of interface nature appears very important at high strain rate. In fact the sample geometry and the interface nature (bonded or not) are enough to confine a PU sample. This mechanism is more important during loading beginning than in confinement test.

This last result verifies the hypothesis that PU from the multi-layer is laterally confined (lateral displacement stopped by the interface nature and interaction area projectile / target small in front of the target area). 


\section{1-D NUMERICAL APPROACH}

In order to validate a behaviour law of PU and multilayer PC/PU, a numerical approach has been developed preliminary to treat the dynamic compressive aspect.

\subsection{Monodimensional finite difference code presentation}

As part of the hypothesis admitted in 3.1, an approach of wave linear propagation is realized. It amounts to consider wave propagation in an elastic bar. Every discretized component is $\Delta \mathbf{x}$ length and all the material characteristics (density, elastic modulus,...) are defined for every segment. The boundary limits conditions verified at the surface for the stresses tensor imply that $\bar{\sigma} \cdot \vec{n}=\overrightarrow{0}$ for $\vec{n}_{1}=[0,1,0]$ and $\vec{n}_{2}=[0,0,1]$.

This hypothesis is also verified in the volume with the condition that the stresses gradient is weak along the $x$ axis. With the dynamical equation of state, we try to explain displacements at $t+1$ time and $i$ element as function of displacements at $t$ time. A coefficient $K_{o}=0.9$ which gives a relation between $\Delta x$ and $\Delta t$ is introduced in order to homogenize strains. A displacement which corresponds to a compression of the two first element is applied as initial condition. Thus, we obtain:

$$
\begin{gathered}
u_{i}^{t+1}=K_{o}^{2} \times\left\{\frac{\left(E_{i}-E_{i-1}\right)}{E_{i}}\left(u_{i}^{t}-u_{i-1}^{t}\right)+\left(u_{i-1}^{t}-2 u_{i}^{t}+u_{i+1}^{t}\right)\right\}+2 u_{i}^{t}-u_{i-1}^{t} \\
\text { with } K_{o}=\frac{\Delta T}{\Delta x} \times C_{L} \text { et } C_{L}=\sqrt{\frac{E_{i}}{\rho_{i}}}
\end{gathered}
$$

\subsection{Results and analysis}

A simulation has been performed (see Figure 6) on a multi-layer $\mathrm{PC}(3 \mathrm{~mm}) / \mathrm{PU}(3 \mathrm{~mm}) / \mathrm{PC}(3 \mathrm{~mm})$ and parameters used are the following:

- total length $\mathrm{L}=9 \mathrm{~mm}, \mathrm{Dx}=0.1 \mathrm{~mm}$,

- for $\mathrm{PC}: \mathrm{E}=2.4 \mathrm{GPa}$ and density $=1.2$,

- for PU : $E=100 \mathrm{MPa}$ (which corresponds to a prestress state but unconfined), density = 1.19,

- incident stress level $=50 \mathrm{MPa}$.

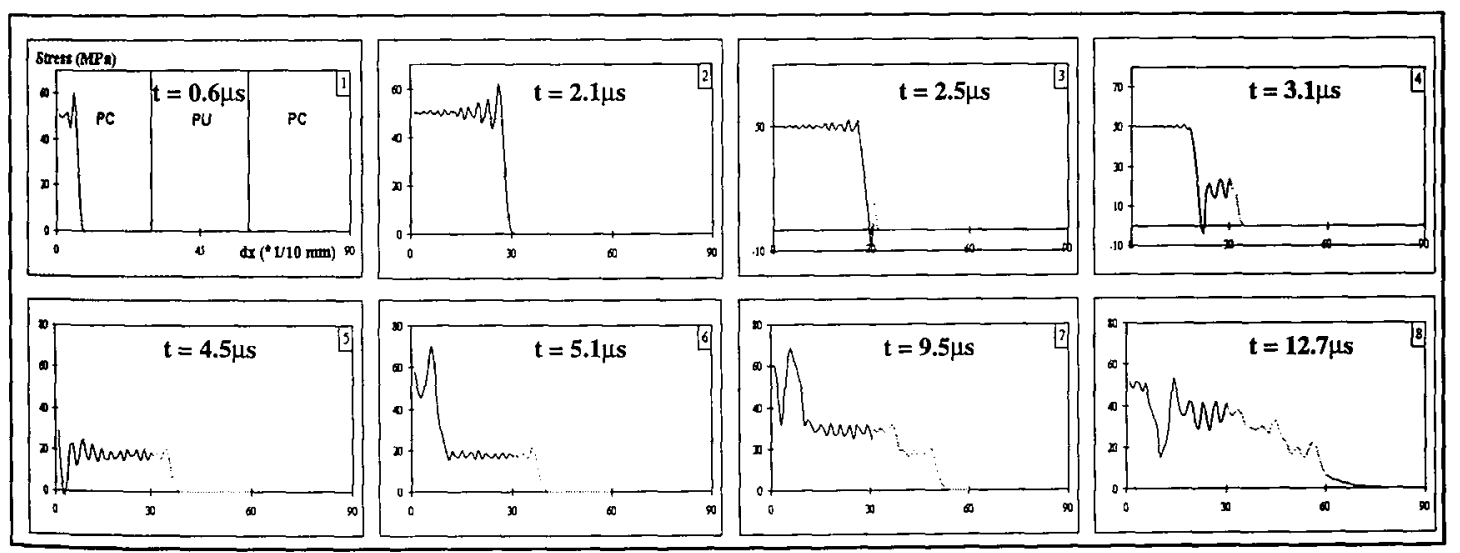

Figure 6: Elastic wave propagation chronology in multi-layered assembly

The incident signal is an Heaveside type in order to understand growing stress level in the different parts of the assembly. The wave velocity in PC is above four times more important than in PU (in our case). Thus, the incident signal is reflected many times before that the transmitted signal at the first interface would have gone totally through PU layer. The wave reflection at the first interface is made in traction and we can notice that the transmitted signal is weak in front of the first. This can be easily explained by the transmission / reflection factors calculated with acoustic impedance ratio (table 3 ).

About the second interface, we can notice that the transmitted signal level (in PC) is twice higher than the PU signal level. To understand this phenomenon, a loading polar diagram as presented on Figure 7 is required. 
This diagram gives for each layer stress level and particle celerity $\left(\sigma_{1}\right.$ value is arbitrary fixed). We observe $\sigma_{2}<<\sigma_{1}$ and $\sigma_{3} \simeq 2 \sigma_{2}$; this comes from the PU particle celerity which is more important than in PC. Globally the incident signal is temporally distributed.

Table 3: Transmission / Reflection coefficients for PC/PU/PC assembly

\begin{tabular}{|c|c|c|}
\cline { 2 - 3 } \multicolumn{1}{c|}{} & Interface 1 & Interface 2 \\
\hline Transmission & $\mathrm{T}_{1}=0.35$ & $\mathrm{~T}_{2}=1.65$ \\
\hline Reflection & $\mathrm{R}_{1}=-0.65$ & $\mathrm{R}_{2}=0.65$ \\
\hline
\end{tabular}

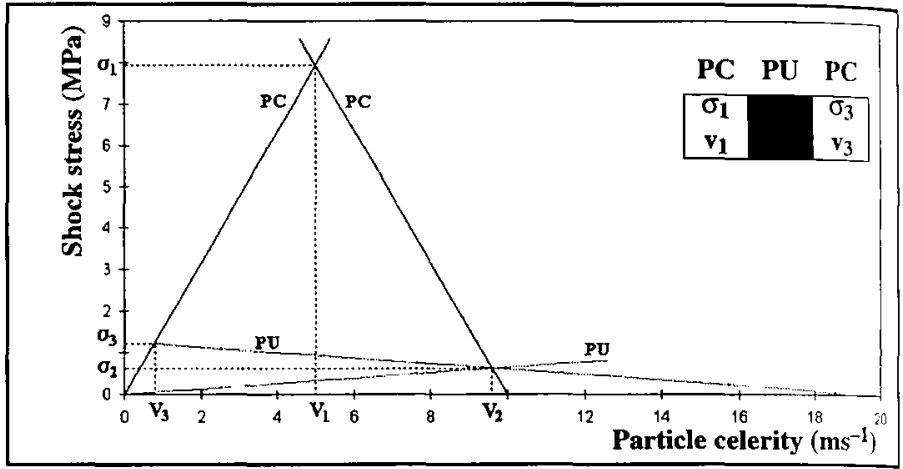

Figure 7: Loading polar diagram for [PC/PU/PC] assembly

\section{CONCLUSION AND PROSPECTS}

An approach of dynamic behaviour (more especially in compression) of multilayered PC/PU used in lightweigth armour was done. The influence of temperature, confinement and bonding on the PU behaviour has been studied. Moreover, preliminary results in compression allow us to verify hypothesis of PU plane strains in the multilayered system.

Nevertheless, this study must be completed with tests on other sample geometries to analyze the sample structure effect (L/d ratio) in compressive solicitations and agreement with the wave propagation modelisation. Beside, it would be interesting to develop a specific test configuration on multilayered samples in order to compare signals recorded with the modelisation proposed. Moreover, the dynamic shear behaviour of multilayered should be investigated before to define a behaviour law.

\section{REFERENCES}

[1] Orsini H., Cottenot C. E., "Specific test to evaluate intrinsic ballistic properties of ceramic materials against an AP $12.7 \mathrm{~mm}$ projectile; Application to improve ceramic materials", Proc. 15th Int. Symp. on Ballistics, Jerusalem, Israel, 1995

[2] Cottenot C. E., "Transparent ceramic for lightweight armours", Lightweight Armours Symposium ' 95 , Cranfield, England, 28-30 June, 1995

[3] Steer P. \& al., "Viscoplasticité dynamique de polycarbonates aux grandes vitesses de déformation, relations structure-propriétés.", Journal de Physique 1985 tome 46 supplément au $\mathrm{n}^{\circ} 8$

[4] Billington E. W. \& al., "Mechanical properties of various polymeric solids tested in compression.", Int. Journal Mechanical Science 1971 Vol. 13 p: $531-545$

[5] Wissler G. E. \& al., "Glass transition in semicrystalline polycarbonate.", Journal of Polymer Science 1980 Vol.18 p: $1257-1270$

[6] G'Sell \& al., "Introduction à la mécanique des polymères.", 1995 INPL-MECAMAT-GFP-APOLLOR-FIRTECH

[7] Bauwens C. \& al., "Effect of thermal history on the tensile yield stress of polycarbonate in the $\beta$ transition range.", Polymer 1983 Vol. 24 july p: 921-924

[8] Bauwens C. \& al., "The temperature dependence of yield of polycarbonate in uniaxial compression and tensile tests.", Journal of Material Science 71972 october p: 176-183

[9] Cottenot C. E., "Comparaison des modes de comportement élémentaires des composites à matrice thermodurcissable et thermoplastique.", Thèse de l'ENSMA. Septembre 1991

[10] Toqueboeuf W., "Etude du comportement dynamique des assemblages: Polycarbonate/Polyuréthanne à finalité balistique", Rapport de stage ingénieur ISIM référence: ETCA 96R041 juin 96

[11] Davies E. D. H. \& al., "The dynamic compression testing of solids by the method of the split Hopkinson pressure bar", Journal of Mechanical Physics of Solids 1963 Vol. 11 p:155-179 